\title{
Влагозащитное покрытие: что необходимо учесть при выборе
}

\author{
Д. Поцелуев, к. э. н. ${ }^{1}$
}

УДК 621.3.049 | ВАК 05.27.06

\begin{abstract}
Защита печатных узлов от различных негативных факторов внешней среды один из ключевых аспектов в процессе производства радиоэлектронной аппаратуры. Особенно если речь идет о производстве электроники ответственного и специального назначения. Правильно подобранные влагозащитное покрытие и технологический процесс его нанесения существенно повышают надежность и длительность работы электронных устройств в неблагоприятных условиях. Ключевые вопросы заключаются в том, как не ошибиться при выборе покрытия? Какому алгоритму следовать? Какие параметры или аспекты учитывать? Как правильно работать с ценовой информацией? В данной статье будут кратко рассмотрены методы выбора влагозащитных покрытий и более детально - аспекты формирования стоимости и влияние покрытий на цену изделия.
\end{abstract}

егодня на рынке представлен широкий ассортимент технологических материалов, предназначенных для защиты электроники от негативных воздействий окружающей среды: уретановые и акриловые лаки, полиуретановые и силиконовые компаунды, эпоксидные смолы, парилен. При большом разнообразии покрытий самым распространенным материалом для защиты печатных узлов от неблагоприятных воздействий окружающей среды остаются лаки - уретановые и акриловые влагозащитные покрытия.

Рассмотрим сначала, какие типы влагозащитных лаков бывают. Такие влагозащитные покрытия разделяют на две большие группы: уретановые и акриловые. Внутри этих групп идет более узкое деление: по вязкости (лак/гель), основе (вода / растворитель), способу применения, наличию сертификата UL. B отдельную группу можно выделить покрытия ультрафиолетового отверждения из-за специализированного метода отверждения, однако по своим характеристикам они ближе к уретановым покрытиям. Несложно запутаться в таком многообразии, учитывая, что разных вариантов лаков более 50. Поэтому у технологов очень часто возникают вопросы по методике правильного выбора влагозащитных покрытий.

Для выбора влагозащитного покрытия не существует определенных регламентов, методологии или правил, поскольку процессы производства электроники специализированы и зачастую крайне индивидуальны. Но существуют общие рекомендации, благодаря которым можно упростить процесс выбора. Схематично алгоритм

ООО «Остек-Интегра», начальник отдела продаж. выбора влагозащитного покрытия представлен на рис. 1. Однако данную схему необходимо дополнить комментариями. Сначала требуется определить диапазон рабочих температур, в котором будет эксплуатироваться электроника. Так как мы говорим о полимерных лаках, диапазон допустимых рабочих температур у них составляет от -65 до $125^{\circ} \mathrm{C}$. Если температура превышает $125^{\circ} \mathrm{C}$, то следует рассматривать силиконовые влагозащитные покрытия.

Далее необходимо определить требования к химической стойкости, то есть будет ли печатный узел подвергаться воздействию химических веществ, солей, грибковых образований и т. п. Наибольшая устойчивость к воздействию химических веществ заявлена для уретановых лаков и лаков ультрафиолетового отверждения, а вот акриловые покрытия рекомендуется использовать только для защиты от повышенной влажности.

Следующий шаг - определить желаемый или требуемый тип полимеризации (отверждения). Под существующие способы отверждения (воздухом, влажностью, температурой, ультрафиолетом) или их комбинацию подходят

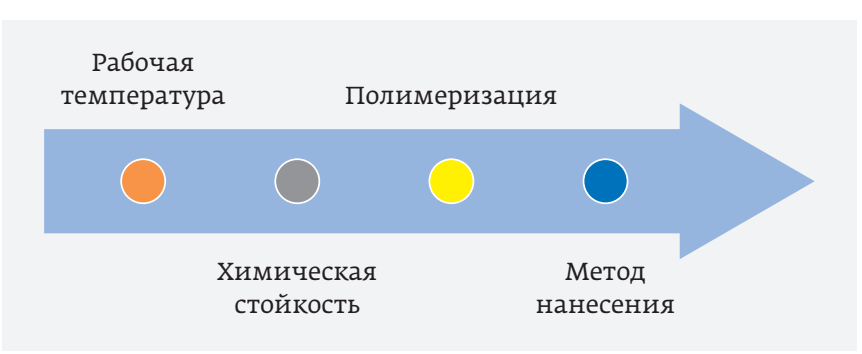

Рис. 1. Алгоритм выбора влагозащитного покрытия 


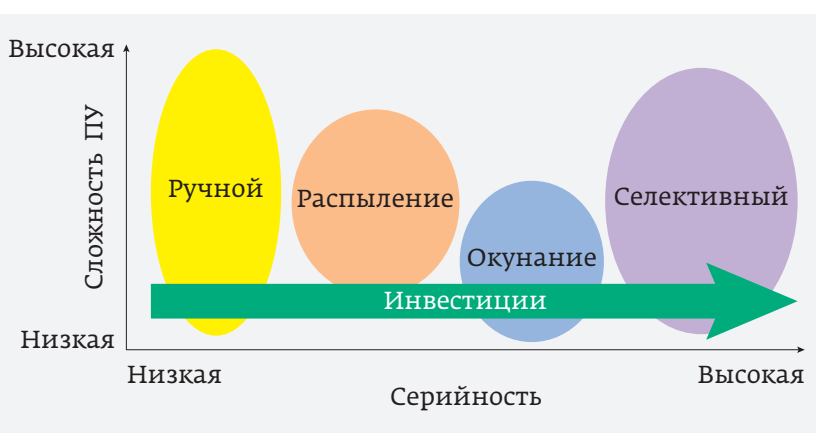

Рис. 2. Методы нанесения влагозащитных покрытий ключевые факторы

определенные типы покрытий. Если возникли затруднения, настоятельно рекомендуем воспользоваться консультацией специалиста.

По методу нанесения ограничений меньше, но они все же есть. Для большинства методов нанесения (кистью, распылением, селективным нанесением, окунанием) подходят практически все влагозащитные покрытия. Тем не менее лаки на водной основе, как правило, ограничены для применения на установках селективного нанесения, а лаки ультрафиолетового отверждения не рекомендуется наносить методом окунания. Метод нанесения влагозащитного покрытия оказывает определяющее воздействие на себестоимость единицы изделия и стоимость технологического процесса в целом. Все производственные факторы учесть очень сложно, но можно ориентироваться на два ключевых: сложность печатного узла (Пу) и серийность (рис. 2).

Ручное нанесение и нанесение путем распыления две самые распространенные технологии нанесения влагозащитных покрытий. Их преимущества заключаются в том, что они не требуют серьезных инвестиций в оборудование, просты в применении, подходят для печатных узлов разной сложности. Однако они имеют и свои недостатки: низкую повторяемость процесса, высокий расход материала, невысокую производительность, отсутствие контроля толщины покрытия.

При средней и высокой серийности производства рекомендуется рассмотреть нанесение влагозащиты окунанием и селективным методом. К преимуществам этих методов можно отнести низкие переменные затраты, высокую производительность, контроль толщины покрытия. Недостатки - более высокие затраты на оборудование и создание специализированного программного обеспечения, а также высокие требования к квалификации персонала. Сравнение различных методов нанесения в обобщенном виде приведено в табл. 1.

Итак, можно считать, что с выбором покрытия мы определились и остановились на нескольких вариантах. Но в итоге выбор надо сделать в пользу одного продукта, и его цена здесь играет не последнюю роль. Зачастую именно цена за единицу измерения (как правило, литр) оказывает определяющее влияние на выбор лака. В условиях жесткой конкуренции и стремлении снизить производственные затраты производители электроники при выборе ориентированы на минимальную цену за литр. В этом нет ничего плохого, но, если не учитывать некоторые технические моменты, самый дешевый продукт может в итоге оказаться более дорогим и наоборот, то есть его цена за единицу измерения не всегда равна конечной стоимости.

Дело в том, что при сравнении и выборе влагозащитных покрытий часто не учитывается такое свойство

Таблица 1. Сравнение методов нанесения влагозащитных покрытий

\begin{tabular}{|c|c|c|c|c|c|c|c|}
\hline \multirow{2}{*}{$\begin{array}{l}\text { Метод } \\
\text { нанесения }\end{array}$} & \multicolumn{5}{|c|}{ Типы покрытий } & \multirow[t]{2}{*}{ Преимущества } & \multirow[t]{2}{*}{ Недостатки } \\
\hline & $\begin{array}{l}\text { Акри- } \\
\text { ловые }\end{array}$ & $\begin{array}{l}\text { Полиуре- } \\
\text { тановые }\end{array}$ & $\begin{array}{l}\text { На основе } \\
\text { раствори- } \\
\text { телей }\end{array}$ & $\begin{array}{l}\text { На } \\
\text { водной } \\
\text { основе }\end{array}$ & $\begin{array}{l}\text { УФ-отвержде- } \\
\text { ния }\end{array}$ & & \\
\hline Кисть & Да & Да & Да & Да & Да & Низкие затраты & $\begin{array}{l}\text { Зависимость от } \\
\text { оператора }\end{array}$ \\
\hline Распыление & Да & Да & Да & Да & Да & Средние затраты & $\begin{array}{l}\text { Избыток лака, } \\
\text { необходимость } \\
\text { маскирования }\end{array}$ \\
\hline $\begin{array}{l}\text { Селективное } \\
\text { нанесение }\end{array}$ & Да & Да & Да & $\begin{array}{l}\text { Нет (как } \\
\text { правило) }\end{array}$ & Да & $\begin{array}{l}\text { Высокие скорость } \\
\text { и повторяемость }\end{array}$ & $\begin{array}{l}\text { Высокие } \\
\text { капитальные } \\
\text { затраты }\end{array}$ \\
\hline Окунание & Да & $\begin{array}{l}\text { Воз- } \\
\text { Можно }\end{array}$ & Да & Да & $\begin{array}{l}\text { Да (в зависи- } \\
\text { мости от обо- } \\
\text { рудования) }\end{array}$ & $\begin{array}{l}\text { Высокая скорость, } \\
\text { покрытие с двух } \\
\text { сторон }\end{array}$ & Дизайн плат \\
\hline
\end{tabular}


Таблица 2. Особенности формирования стоимости влагозащитных покрытий

\begin{tabular}{lccc} 
Тип влагозащитного покрытия & Содержание твердых частиц, \% & Цена за литр & Стоимость \\
Покрытие на основе синтетического каучука & 25 & $X$ & X/0,25=4X \\
\hline Уретановое покрытие на основе растворителей & 40 & $1,1 X$ & $1,1 X / 0,40=2,75 X$ \\
\hline Покрытие ультрафиолетового отверждения & 100 & $2 X$ & $2 X / 1,0=2 X$ \\
\hline
\end{tabular}

материала, как содержание твердых частиц. Твердые частицы - это основа лака, которая после полимеризации остается на поверхности печатного узла. Их содержание может существенно различаться в зависимости от продукта. Исторически все защитные покрытия производят с содержанием частиц меньше 100\% по нескольким причинам:

- для снижения вязкости с целью удобного нанесения;

- для повышения адгезионных свойств путем добавления специальных присадок.

Более 75\% влагозащитного покрытия составляют различные присадки и агенты, которые не влияют на конечные свойства покрытия, но критически необходимы для производственного процесса. Таким образом, сравнение цены без учета содержания количества твердых частиц во влагозащитном покрытии получится некорректным. Давайте рассмотрим это на примере (табл. 2).

Покрытия ультрафиолетового отверждения, как правило, существенно дороже традиционных акриловыхили уретановых и нередко вызывают “ценовой шок" у представителей отдела закупок. Но фактически покрытия УФ-отверждения могут обеспечить бо́льшую выгоду и наименьшие затраты на единицу изделия в процессе производства.

Конечно, УФ-покрытия подходят не для каждого технологического процесса и требуют специализированного

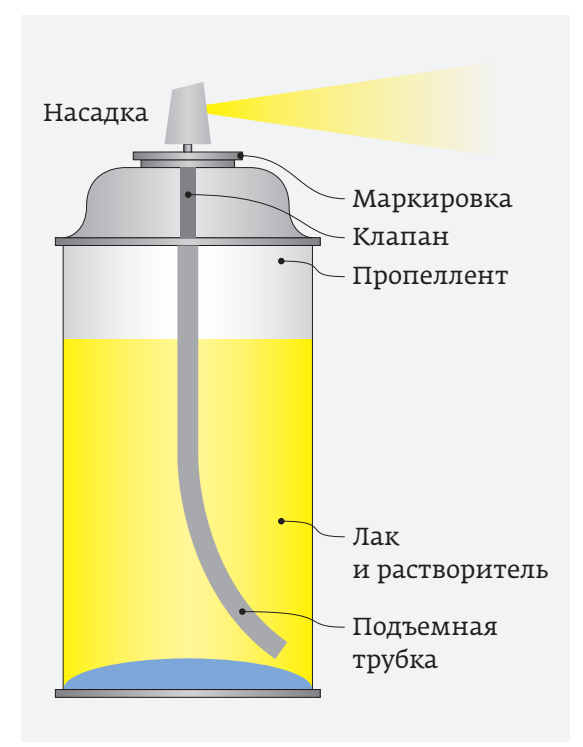

Рис. 3.

Конструкция аэрозольного баллона оборудования. Но приведенная выше методика эффективна также и для сравнения традиционных влагозащитных покрытий. Очень яркий пример можно привести с влагозащитными покрытиями в аэрозольных баллонах. Это довольно популярный и, на первый взгляд, выгодный способ защитить печатный узел уретановым или акриловым лаком. Но давайте обратимся к нашему опыту и проанализируем количество твердых частиц. В стандартном аэрозольном баллоне оно составляет порядка 6-8\%. Однако, помимо лака, в баллоне присутствует еще пропеллент, чтобы пользователь смог его распылять (рис. 3). Поэтому из заявленных 250 или 400 мл объема баллона самого лака в нем находится гораздо меньше. С учетом всех этих факторов стоимость покрытия площади печатного узла в пересчет на литры увеличивается в 4-6 раз по сравнению со стандартным методом ручного нанесения или распыления через пульверизатор.

Безусловно, существует еще множество факторов, которые можно и нужно принимать во внимание при выборе влагозащитных покрытий: компетенции поставщика, уровень сервиса и технологической поддержки, репутация и профессионализм компании, технологичность и свойства материала, требования по безопасности для персонала и т.д. Но так как вопросы цены и стоимости имеют первостепенное значение, необходимо под разными углами оценивать задачи по выбору технологическихматериалов и правильно пересчитывать цену за единицу измерения в конечную стоимость.

ООО «Остек-Интегра» является официальным эксклюзивным дистрибьютором компаний DOW (влагозащитные покрытия под маркой Dowsil ${ }^{\circledR}$ ) и Chase Corporation (влагозащитные покрытия под маркой HumiSeal ${ }^{\circledR}$ ). Накопленные опыт и знания, широкая номенклатура материалов, наличие сертифицированного специалиста IPC и собственного отдела технологической поддержки, доступ к исследовательским центрам мирового уровня позволяют компании ООО "Остек-Интегра" решать индивидуальные уникальные задачи различного уровня сложности.

В ООО "Остек-Интегра" можно получить консультации по любым вопросам, касающимся технологических материалов и связанных с ними процессов, а также ознакомиться с основной номенклатурой материалов, поставляемых компанией. 

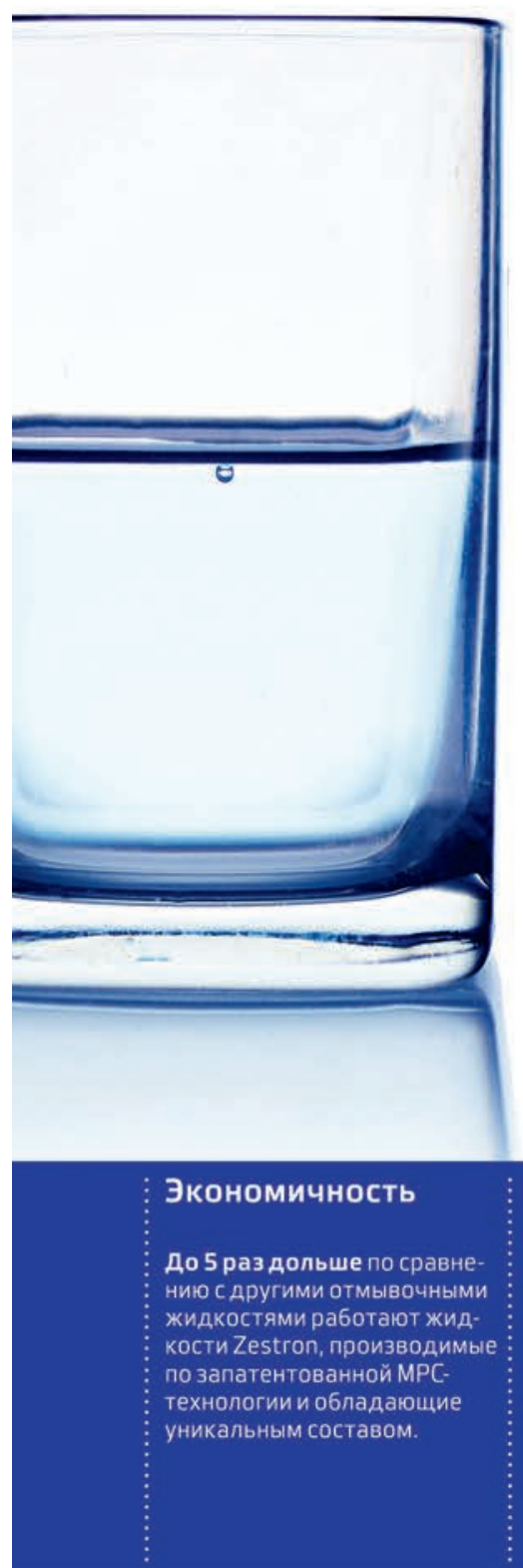

Подтвержденное качество

Более 10 пет жидкости

Zestron успешно применяютсяв отечественном произ. водстве РЭА ответственного ивоенного назначения. обеспечивая высокое каче ство отмывки и надежный результат.
Максимапьная совместимость

Уникапьный состав обеспечивает максимальную совместимость жидкостей совсеми узлами идеталями оборудования для отмывки способствуя продолжительному сроку службы оборудования и минимизируя расходына обслуживание ипростои.

\section{Контропь} и стабильность

Только Zestron предлагает специальные тестовые на6о рыдля контроля состояния раствора отмывочных жид костей для своевременной корректировки концентрации и состояния раствора, обеспечивая максимальную стабильность и надежность процесса отмывки.

\section{ZIFSTIRT}

High Precision Cleaning

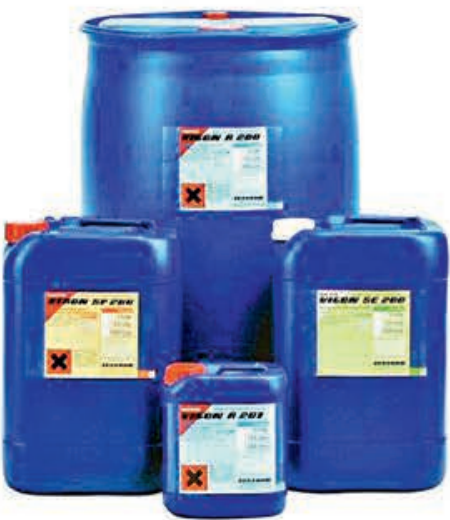

Никаких полумер. Вся полнота преимуществ

Оригинальные отмывочные жидкости Zestron гарантируют непревзойденное качество отмывки и стабильность результата. Широкий ассортиментный ряд позволяет подобрать отмывочную жидкость для конкретной задачи: в соответствии с типом оборудования и процесса, характером загрязнений, индивидуальными требованиями.

Отличительной особенностью отмывочных жидкостей Zestron является высокая эффективность: качественная отмывка, совместимость с оборудованием и компонентами, экономичность. Жидкости Zestron успешно зарекомендовали себя на ведущих отечественных производствах РЭА.

Официальный эксклюзивный дистрибьютор Zestron Группа компаний Остек обеспечивает высококвалифицированную техническую и технологическую поддержку, поставку со скпада и оперативную доставку по всей России с соблюдением всех условий транспортировки и хранения. 